\title{
Determination of Dodecanol and Short-Chained Ethoxylated Dodecanols by LC-MS/MS (with Electrospray Ionization) After Their Derivatization (with Phenyl Isocyanate)
}

\author{
Joanna Zembrzuska ${ }^{1}$
}

Received: 15 November 2016/Accepted: 23 August 2017/Published online: 9 September 2017

(c) The Author(s) 2017. This article is an open access publication

\begin{abstract}
This report describes the application of LC-MS/ $\mathrm{MS}$ for the separation of dodecanol $\left(\mathrm{C}_{12} \mathrm{OH}\right)$ and homogenous fatty alcohols ethoxylated (AE) containing a dodecyl moiety and 1-9 ethoxy groups. These ethoxylates and free alcohol were derivatized for LC-MS/MS analysis with phenyl isocyanate (PIC). The derivatives of analytes with PIC were separated using a C18 column. Gradient elution with a mixture of ethyl acetate and acetonitrile (5 mM) was employed. The described determination method is characterized by low detection limits (range from $0.005 \mu \mathrm{g} \mathrm{L}^{-1}$ for: $\mathrm{C}_{12} \mathrm{OH}, \mathrm{C}_{12} \mathrm{EO}_{2-7}$ to $1 \mu \mathrm{g} \mathrm{L}{ }^{-1}$ for $\mathrm{C}_{12} \mathrm{EO}_{1}$ ) and quantification limits (range from $0.01 \mu \mathrm{g} \mathrm{\textrm {L } ^ { - 1 }}$ for: $\mathrm{C}_{12} \mathrm{EO}_{5-7}$ to $2 \mu \mathrm{g} \mathrm{L}{ }^{-1}$ for $\mathrm{C}_{12} \mathrm{EO}_{1}$ ). The developed and validated method was used in combination with liquidliquid extraction (using ethyl acetate) in order to identify and quantitatively determine the $\mathrm{C}_{12} \mathrm{OH}$ and $\mathrm{C}_{12} \mathrm{EO}_{1-9}$ present in environmental samples collected from Warta river water in Poznan.
\end{abstract}

Keywords Alcohol ethoxylates · LC-MS/MS ·

Derivatization - LLE - River water · Phenyl isocyanate · Dodecanol

Electronic supplementary material The online version of this article (doi:10.1007/s11743-017-2015-z) contains supplementary material, which is available to authorized users.

Joanna Zembrzuska

Joanna.Zembrzuska@put.poznan.pl

1 Institute of Chemistry and Technical Electrochemistry, Poznan University of Technology, Berdychowo 4, 60-965 Poznan, Poland

\section{Introduction}

Non-ionic ethoxylated surfactants are common pollutants of the aquatic environment due to their multiple uses as components in the manufacture of laundry detergents, industrial cleaning products and polyurethanes, solubilizers in enhanced oil recovery, emulsifiers in pharmaceutical preparations, additives in cosmetic creams and lotions as well as dispersing and wetting agents [1].

Aliphatic alcohol ethoxylates (AE) are the most important group of non-ionic surfactants and are commonly found in surface water and wastewater [2]. This is associated with the scale of their production, which reached 1 billion tons in 2012 [3]. These compounds are characterized by rapid degradation and low toxicity of some of their biodegradation products, including the formation of free alcohol, ethoxylated polyols and short chain ethoxylated alcohols.

It has been established that $\mathrm{AE}$ are degraded according to two dominant mechanisms. The first, which is predominant, is central fission, which results in the formation of a hydrophobic part (free fatty alcohol) and hydrophilic polyethylene glycols (PEGs) [4, 5]. The second mechanism is the stepwise shortening of the ethoxyl chain by removal of single ethoxyl groups [5], mechanism occurring in the environment is associated with $\Omega$-oxidation of the alkyl and ethoxyl part [5, 6]. As a result, ethoxylated alcohols with different ethoxyl chain length, free alcohols and polyethylene glycols are present in wastewater as well as surface water [5, 7].

Analytical methods for the determination of AE include gas chromatography [8], normal-phase high-performance liquid chromatography and reversed-phase HPLC with isocratic and gradient elution [9-11]. Separation of ethoxylated surfactants has been performed using capillary 
gel electrophoresis (CGE), capillary zone electrophoresis (CZE) [12, 13], micellar electrokinetic chromatography (MEKC) [1], non-aqueous capillary electrophoresis (NACE) [14] and capillary electrochromatography (CEC) [1].

Different detectors can be used for determination of ethoxylated surfactants. The most popular are the ultraviolet detector (UV) [15-17], fluorescence detector [10, 18], flame ionization detector (FID) [19], evaporative lightscattering detector (ELSD) [20, 21], corona-charged aerosol detector (CAD) [1], MS detector and MS/MS detector $[6,11,18,22-26]$.

The lack of a chromophore in the AE molecule in many cases requires the use of a suitable derivatization processes to improve the sensitivity when UV and fluorescence are used. In this case, the most commonly used derivatization agents include 3,5-dinitrobenzoyl chloride [15], naphthyl isocyanate [10, 15], diphenic anhydride [27], naphthoyl chloride [10], phenyl isocyanate $[16,17,28]$.

The use of a MS or MS/MS detector for quantitative or qualitative determination of $\mathrm{AE}$, which contain two or more ethoxy groups in their structure, does not require the derivatization process [23]. Unfortunately, due to their structure, the free alcohol and $\mathrm{AE}$ with a single ethoxy group (1 or 2 ) are unstable in the ESI ion source and therefore it is not possible to observe them in the mass spectrum. Therefore, studies regarding the determination of AE after biodegradation processes focused only on the percentage content of these compounds [7]. Most publications are focused on the evaluation of $\mathrm{AE}$ exposure in environmental compartments. In almost all of these methods, free alcohols (AO) and low ethoxymers are not detected.

As a result, the above-mentioned compounds should be subjected to a derivatization process prior to their introduction into the LC-MS or LC-MS/MS system, in order to allow for the determination of their presence and subsequent analysis of their quantitative changes during the biodegradation process. Such an approach allows one to determine the content of specific AE including a 12 carbon atom hydrophobic chain connected with a hydrophile which included from 0 to 9 ethoxyl groups.

Over the years, chemical derivatization techniques were developed to enable the ionization of various analytes in LC-MS [27]. Numerous methods employing LC-MS have been developed for $\mathrm{AE}$ analysis without derivatization $[6,24,25,29,30]$ and after derivatization [7, 29, 31, 32].

There are several derivatization agents described in the literature which may be employed for the determination of ethoxylates with ESI-LC-MS. Dunphy et al. [33] used 2-fluoro- $N$-methylpyridinium salts as derivatizating agents for determination of free alcohols and low ethoxymers. The group of Ramis-Ramos [34] has published interesting applications for the following analytical characterization reagents: maleic anhydride, phthalic anhydride, and diphenic anhydride. Sparham et al. [35] and Cassani et al. [36] determined the total amount of $\mathrm{AE}$ in the form of 1-naphthoyl chloride derivatives using the LC-MS/MS technique. A quantitative determination of dodecanol and $\mathrm{C}_{12} \mathrm{EO}_{1-6}$ using the LC-MS/MS technique in MRM mode was described by Zgola-Grzeskowiak et al. [18]. In this case, 1-naphthoyl chloride was also used as the derivatization agent.

Phenyl isocyanate (PIC) was proposed previously as a derivatizating agent. PIC was used to derivatize $\mathrm{AE}$ in raw and treated sewage and river water [16] and was also often used to derivatize poly(ethylene glycol)s [1,3]. Detection of $\mathrm{AE}$ derivatives with phenyl isocyanate was conducted using an UV detector at $240 \mathrm{~nm}[16,33]$. There are currently no reports regarding detection with the use of MS/ MS techniques in the MRM mode. This technique allows for sensitive and selective determination of free alcohol and single ethoxylated alcohols, due to the use of MRM mode.

The use of derivatization during LC-MS/MS determination allows to increase the mass of the pseudomolecular ion, improves its stability in the ion source and enhances the ionization efficiency. As a result, it is possible to determine weakly ionized analytes.

In studies in which PIC was used during the derivatization of $\mathrm{AE}$ for their chromatographic determination with UV detection in wastewater, it was observed that signals of derivatives of other contaminants, which were also present in the sample, are visible on the chromatogram. The signals often prevented or hampered the separation of $\mathrm{AE}$ [16]. This problem is eliminated by employing the LC-MS/MS method working in the MRM mode.

The aim of this study was to explore the possibility of using PIC as a derivatization agent for quantitative determination of free alcohol and AE with 1-9 ethoxy groups using the LC-MS/MS technique.

The selection of the $\mathrm{C}_{12} \mathrm{EO}_{x}$ series is not random, since this series is formed both from renewable and petrochemical sources. Therefore, it is an adequate fingerprint which describes the level of water contamination with non-ionic surfactants [37]. Another reason to direct the focus on the $\mathrm{C}_{12} \mathrm{EO}_{1-9}$ series and dodecanol is the availability of homologous reference standards of this series. Unfortunately, the reference standards for homologues with a higher amount of ethoxyl groups in the compound are not available to date. 


\section{Experimental}

\section{Reagents and Chemicals}

Individual alcohol ethoxylates $\mathrm{C}_{12} \mathrm{EO}_{X}(x=1 ; 2 ; 3 ; 4 ; 5$; $6 ; 7 ; 8 ; 9)$ and $\mathrm{C}_{12} \mathrm{OH}$ used as standards were obtained from Fluka (Germany), and $\mathrm{C}_{12} \mathrm{EO}_{3}$ was from Sigma-Aldrich (ST. Louis, MO, USA). All standards were of high purity grade $(>98 \%)$. MS-grade acetonitrile and MS-grade methanol were from Sigma-Aldrich (ST. Louis, MO, USA). Ammonium acetate used as mobile phase additive was purchased from Sigma-Aldrich (ST. Louis, MO, USA). Water was prepared by reverse osmosis in a Demiwa system via double distillation in a quartz apparatus. Only freshly distilled water was used. Phenyl isocyanate $(>99 \%)$ used as a derivatization agent was purchased from Fluka (Germany).

Ethyl acetate, sodium chloride and hydrogen carbonate (purchased from POCh Gliwice Poland) used for liquidliquid extraction (LLE) were of analytical grade.

Standard stock solutions (of each compound) were prepared in acetonitrile and kept at $4{ }^{\circ} \mathrm{C}$.

\section{Derivatization}

PIC $(25.5 \mu \mathrm{L})$ was added to a sample containing $10 \mu \mathrm{g}$ of $\mathrm{C}_{12} \mathrm{OH}$ and $\mathrm{C}_{12} \mathrm{EO}_{1-9}$ in $200 \mu \mathrm{L}$ of acetonitrile. The solution was heated at $70{ }^{\circ} \mathrm{C}$ for $30 \mathrm{~min}$. Then, $10 \mu \mathrm{L}$ of methanol was added and the sample was heated again at $70{ }^{\circ} \mathrm{C}$ for $30 \mathrm{~min}$. Finally, the solution was evaporated by increasing the temperature to $80^{\circ} \mathrm{C}$. The dry residue was re-suspended in the mobile phase to a final volume of $1 \mathrm{~mL}$ and filtered through a syringe PTFE filter before subjecting it to LC-MS/MS. Examples of the derivatization reactions of $\mathrm{C}_{12} \mathrm{OH}$ and $\mathrm{C}_{12} \mathrm{EO}_{1}$ with phenyl isocyanate are shown in Fig. 1a, b, respectively.
Optimization of the Derivatization Procedure

The following parameters were studied during the optimization of the derivatization procedure: time of the derivatization process (from 10 to $60 \mathrm{~min}$, with a 10-min interval), temperature (from 30 to $90{ }^{\circ} \mathrm{C}$ with a $10^{\circ} \mathrm{C}$ interval) and the amount of the derivatization agent relative to $\mathrm{AO}$ and $\mathrm{AE}$ (1:1 with a 25, 50 and $100 \%$ excess). Each of the samples with optimized parameters was prepared in three replicates.

\section{Liquid-Liquid Extraction (LLE)}

The procedure of liquid-liquid extraction of $\mathrm{AE}$ was previously described by Zembrzuska et al. [23]. $15 \mathrm{~g}$ of sodium chloride and $0.1 \mathrm{~g}$ of sodium hydrogen carbonate were added to $50 \mathrm{~mL}$ of the water sample. The sample was extracted with three portions $(10,10$ and $5 \mathrm{~mL}$ respectively) of ethyl acetate. An aliquot $(5 \mathrm{~mL})$ of the combined extracts was evaporated under a gentle stream of nitrogen, reconstituted in acetonitrile and derivatized. This procedure was employed in order to separate and determine the $\mathrm{C}_{12} \mathrm{OH}$ and $\mathrm{C}_{12} \mathrm{EO}_{1-9}$ in water samples collected from the Warta river. The water samples were collected from the Warta river (in Poznan at the measurement and control point on St. Roch Bridge) in accordance with the Polish standard PN EN ISO 566-6:2003. The collecting point was situated upstream of the effluent of the Kozieglowy sewage treatment plant. Samples were collected from the main stream of the river from a depth of $1.0 \mathrm{~m}$. Immediately after transportation to the laboratory in the clean amber glass bottles, the samples were filtered to remove suspended solids using quantitative paper filters, and then subjected to liquid-liquid extraction using ethyl acetate as the extracting agent. The bottles and paper filters were seasoned by an addition of a portion of water in order to prevent adsorptive loss. The extraction was performed

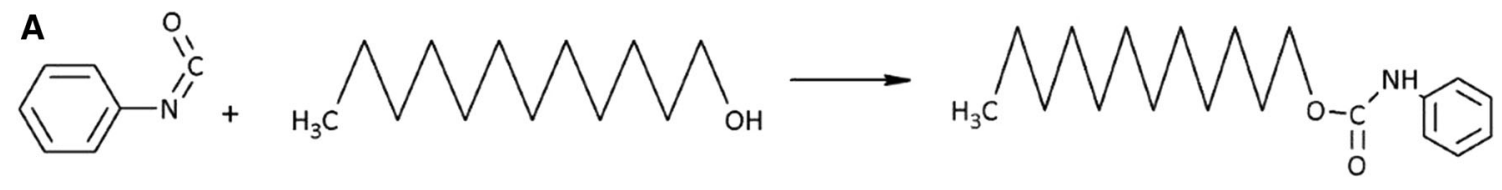

B

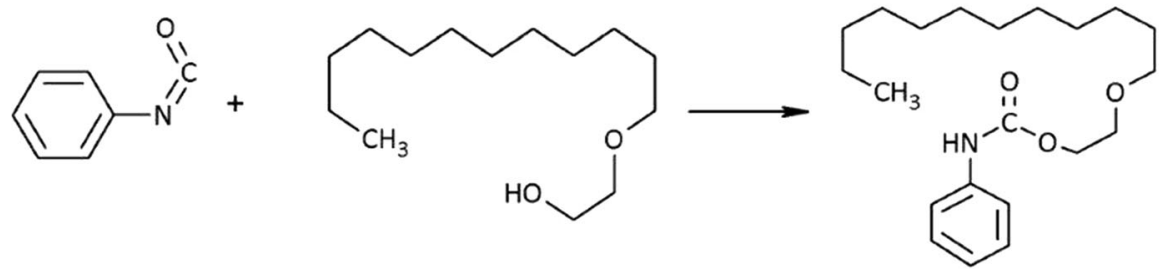

Fig. 1 Derivatization reactions of $\mathrm{C}_{12} \mathrm{OH}$ (a) and $\mathrm{C}_{12} \mathrm{EO}_{1}$ (b) with phenyl isocyanate 
immediately after collection of samples (the sampling point was near the laboratory).

Samples were collected in March 2015. Fifty milliliters of each water sample was extracted. The extraction of water and water spiked standard mixture at three different concentrations $\left(2,4\right.$ and $\left.8 \mu \mathrm{g} \mathrm{L}^{-1}\right)$ was carried out. The samples used for the procedure of extraction and analysis of river water samples were prepared in 3 replicates.

\section{Liquid Chromatography-Tandem Mass Spectrometry}

LC analysis was performed using the UltiMate 3000 RSLC chromatographic system from Dionex (Sunnyvale, CA, USA). Five $\mu \mathrm{L}$ samples were injected into an analytical column $100 \mathrm{~mm} \times 2.1 \mathrm{~mm}$ I.D packed with $1.9 \mu \mathrm{m}$ Hypersil Gold C18 RP from Thermo Scientific (USA). The column was heated to $35^{\circ} \mathrm{C}$. The mobile phase was composed of $5 \mathrm{mM}$ ammonium acetate in water (A) and acetonitrile (B), at a flow rate of $0.2 \mathrm{~mL} / \mathrm{min}$. The gradient elution was: $0 \min 40 \%$ B, $10 \min 60 \%$ B, $20 \min 100 \%$ B, 25 min $100 \%$ B. The LC system was connected to the API 4000 QTRAP triple quadrupole mass spectrometer produced by AB Sciex (Foster City, CA, USA). The Turbo Ion Spray source operated in positive ion mode. Dodecanol and all alcohol ethoxylates were detected using multiple reaction monitoring mode (MRM). ESI ion source parameters were: curtain gas $10 \mathrm{psi}$, nebulizer gas $40 \mathrm{psi}$, auxiliary gas $45 \mathrm{psi}$, temperature $350^{\circ} \mathrm{C}$, ion spray voltage $5500 \mathrm{~V}$ and collision gas set to medium. Table 1 shows the MS/MS parameters used for quantitative dodecanol and AE determination. In the optimized conditions, the $[\mathrm{M}+\mathrm{H}]^{+}$ adducts of $\mathrm{C}_{12} \mathrm{OH}, \mathrm{C}_{12} \mathrm{EO}_{1-3}$ and $\mathrm{C}_{12} \mathrm{EO}_{8-9}$, and $\left[\mathrm{M}+\mathrm{NH}_{4}\right]^{+}$adducts of $\mathrm{C}_{12} \mathrm{EO}_{4-7}$ were used as precursor ions.

\section{Method Validation}

The limits of detection (LOD) for each derivative of $\mathrm{AE}$ homologues and $\mathrm{AO}$, defined as the concentrations which yielded $\mathrm{S} / \mathrm{N}$ ratios greater than or equal to 3 , and the limits of quantification (LOQ), defined as the concentrations which yielded $\mathrm{S} / \mathrm{N}$ ratios greater than or equal to 10 , were determined for $\mathrm{AO}$ and $\mathrm{AE}$ homologues in the mobile phase (the solvent used for the introduction of dodecanol and ethoxylates into the LC-MS/MS system) [38]. In order to determine LOD and LOQ, the peak height above the baseline was measured (signal). The peak-to-peak (minimum to maximum) value of baseline noise away from the peak tails for $60 \mathrm{~s}$ before the peak was measured [39]. Each analysis was carried out in 3 replicates.

Method limits of detection (MDL) and method limit of quantification (MQL) were calculated based on LOD and
LOQ taking into account the concentration factors from river water extraction procedure and the sample dilution factors.

In order to check linearity, mixtures of standards were prepared with the concentration of each component in the range of $0.005-1000 \mu \mathrm{g} \mathrm{L}^{-1}$.

\section{Results and Discussion}

\section{Optimization of MS/MS Conditions}

The first stage of the study aimed to determine the type of ions which could be for detection of $\mathrm{C}_{12} \mathrm{OH}$ and $\mathrm{AEO}_{1-9}$ derivatives with PIC. By using ammonium acetate as an addition to the phase, it was possible to obtain $\left[\mathrm{M}+\mathrm{NH}_{4}\right]^{+}$ ions as well as $[\mathrm{M}+\mathrm{H}]^{+}$ions. In case of $\mathrm{C}_{12} \mathrm{OH}$ and $\mathrm{AEO}_{1}$ only the presence of $[\mathrm{M}+\mathrm{H}]^{+}$ions was observed in the mass spectrum. Both adducts were visible on the mass spectrum for the remaining AE. Therefore, MRM chromatograms with protonated or ammoniated adducts as precursor ions were obtained initially (Fig. 1S—see Supporting Information). The peaks of adducts which served as pseudomolecular ions in quantitative and qualitative analyzes of actual samples were based on the chromatographic peak areas for specific derivatives of $\mathrm{AEO}_{2-9}$. In case of $\mathrm{C}_{12} \mathrm{EO}_{4}, \mathrm{C}_{12} \mathrm{EO}_{6}, \mathrm{C}_{12} \mathrm{EO}_{7}$ these were $\left[\mathrm{M}+\mathrm{NH}_{4}\right]^{+}$ions, whereas $[\mathrm{M}+\mathrm{H}]^{+}$were used for $\mathrm{C}_{12} \mathrm{EO}_{2}, \mathrm{C}_{12} \mathrm{EO}_{3}, \mathrm{C}_{12} \mathrm{EO}_{5}$, $\mathrm{C}_{12} \mathrm{EO}_{8}$ and $\mathrm{C}_{12} \mathrm{EO}_{9}$.

\section{Fragmentation of AE Derivatives with PIC}

Fragmentation of protonated or ammoniated derivatives of $\mathrm{C}_{12} \mathrm{EO}_{1-9}$ homologues and $\mathrm{C}_{12} \mathrm{OH}$ was investigated. Collision conditions were optimized automatically by the spectrometer program and are given in Table 1. The results, together with chromatograms with MRM detection, are shown in Figs. 2 and 3. In case of $\mathrm{C}_{12} \mathrm{OH}$ and $\mathrm{C}_{12} \mathrm{EO}_{1}$ only the detection of protonated adducts was possible and a single transfer between the pseudomolecular ion and the fragmentation ion was determined.

The fragmentation spectra of ammoniated ions (Fig. 3) differ from the spectra of protonated ions due to the presence of one additional fragment, i.e. the formation of a protonated ion. The signals with the highest intensity, which are visible on the fragmentation spectra, originate from the protonated ions of $\mathrm{AE}$ derivatives with PIC $[\mathrm{M}+\mathrm{H}]^{+}$, e.g. $\mathrm{C}_{12} \mathrm{EO}_{5}-m / z=526$ (Figs. 2, 3); whereas the signals with lower intensity occur due to the loss of phenyl isocyanate or subsequent ethoxy groups from the AE molecule. The signal at $\mathrm{m} / \mathrm{z}=164$, which is present on every spectrum, occurs due to the loss of a fragment of the phenyl isocyanate $-\mathrm{OCH}_{2} \mathrm{CH}_{2}$ - unit, e.g. in case of $\mathrm{C}_{12} \mathrm{EO}_{5}$ 
Table 1 MS/MS parameters for the acquisition of dodecanol and alcohol ethoxylates

\begin{tabular}{|c|c|c|c|c|c|c|c|c|c|c|c|}
\hline Compound & Precursor ion $[\mathrm{M}+\mathrm{H}]^{+} \mathrm{m} / z$ & \multicolumn{2}{|c|}{ Declustering potential [V] } & \multicolumn{2}{|c|}{$\mathrm{MRM} 1^{\mathrm{a}}$} & \multicolumn{2}{|c|}{ Collision energy [V] } & \multicolumn{2}{|c|}{$\operatorname{MRM} 2^{\mathrm{b}}$} & \multicolumn{2}{|c|}{ Collision energy $[\mathrm{V}]$} \\
\hline $\mathrm{C}_{12} \mathrm{OH}^{\mathrm{c}}$ & 306 & \multicolumn{2}{|c|}{76} & \multicolumn{2}{|c|}{$306 \rightarrow 138$} & \multicolumn{2}{|l|}{17} & \multicolumn{2}{|l|}{-} & \multicolumn{2}{|l|}{-} \\
\hline $\mathrm{C}_{12} \mathrm{EO}_{1}^{\mathrm{c}}$ & 350 & \multicolumn{2}{|c|}{90} & \multicolumn{2}{|c|}{$350 \rightarrow 164$} & \multicolumn{2}{|l|}{19} & \multicolumn{2}{|l|}{-} & \multicolumn{2}{|l|}{-} \\
\hline $\mathrm{C}_{12} \mathrm{EO}_{2}^{\mathrm{c}}$ & 394 & \multicolumn{2}{|c|}{106} & \multicolumn{2}{|c|}{$394 \rightarrow 164$} & \multicolumn{2}{|l|}{23} & \multicolumn{2}{|c|}{$394 \rightarrow 275$} & 15 & \\
\hline $\mathrm{C}_{12} \mathrm{EO}_{3}^{\mathrm{c}}$ & 438 & \multicolumn{2}{|c|}{96} & \multicolumn{2}{|c|}{$438 \rightarrow 319$} & \multicolumn{2}{|l|}{17} & \multicolumn{2}{|c|}{$438 \rightarrow 164$} & 25 & \\
\hline $\mathrm{C}_{12} \mathrm{EO}_{4}$ & 482 & \multicolumn{2}{|c|}{41} & \multicolumn{2}{|c|}{$482 \rightarrow 271$} & \multicolumn{2}{|l|}{13} & \multicolumn{2}{|c|}{$482 \rightarrow 120$} & 41 & \\
\hline $\mathrm{C}_{12} \mathrm{EO}_{5}^{\mathrm{c}}$ & 526 & \multicolumn{2}{|c|}{71} & \multicolumn{2}{|c|}{$526 \rightarrow 407$} & \multicolumn{2}{|l|}{19} & $526 \rightarrow$ & 164 & 35 & \\
\hline $\mathrm{C}_{12} \mathrm{EO}_{6}$ & 570 & 86 & & 570 & $\rightarrow 451$ & 19 & & $570 \rightarrow$ & 164 & 27 & \\
\hline $\mathrm{C}_{12} \mathrm{EO}_{7}$ & 614 & 136 & & 614 & $\rightarrow 495$ & 21 & & $614 \rightarrow$ & 460 & 23 & \\
\hline $\mathrm{C}_{12} \mathrm{EO}_{8}^{\mathrm{c}}$ & 658 & 121 & & 658 & $\rightarrow 540$ & 21 & & $658 \rightarrow$ & 164 & 29 & \\
\hline $\mathrm{C}_{12} \mathrm{EO}_{9}^{\mathrm{c}}$ & 702 & 126 & & 702 & $\rightarrow 584$ & 27 & & $702 \rightarrow$ & 164 & 27 & \\
\hline Compound & Precursor ion $\left[\mathrm{M}+\mathrm{NH}_{4}\right]^{+} \mathrm{n}$ & & Declustering potential & [V] & MRM & & Collision ener & gy [V] & MR & $\mathrm{M} 2^{\mathrm{b}}$ & $\begin{array}{l}\text { Collision } \\
\text { energy [V] }\end{array}$ \\
\hline $\mathrm{C}_{12} \mathrm{EO}_{2}$ & 411 & & 48 & & $411 \rightarrow$ & 395 & 11 & & 411 & $\rightarrow 275$ & 20 \\
\hline $\mathrm{C}_{12} \mathrm{EO}_{3}$ & 455 & & 56 & & $455 \rightarrow$ & 320 & 19 & & 455 & $\rightarrow 439$ & 14 \\
\hline $\mathrm{C}_{12} \mathrm{EO}_{4}^{\mathrm{c}}$ & 499 & & 50 & & $499 \rightarrow$ & 364 & 23 & & 499 & $\rightarrow 164$ & 23 \\
\hline $\mathrm{C}_{12} \mathrm{EO}_{5}$ & 543 & & 110 & & $543 \rightarrow$ & 527 & 20 & & 543 & $\rightarrow 408$ & 24 \\
\hline $\mathrm{C}_{12} \mathrm{EO}_{6}^{\mathrm{c}}$ & 587 & & 70 & & $587 \rightarrow$ & 452 & 26 & & 587 & $\rightarrow 571$ & 21 \\
\hline $\mathrm{C}_{12} \mathrm{EO}_{7}^{\mathrm{c}}$ & 631 & & 96 & & $631 \rightarrow$ & 496 & 28 & & 631 & $\rightarrow 164$ & 22 \\
\hline $\mathrm{C}_{12} \mathrm{EO}_{8}$ & 675 & & 99 & & $675 \rightarrow$ & 541 & 28 & & 675 & $\rightarrow 164$ & 35 \\
\hline $\mathrm{C}_{12} \mathrm{EO}_{9}$ & 719 & & 90 & & $719 \rightarrow$ & 584 & 29 & & 719 & $\rightarrow 164$ & 37 \\
\hline
\end{tabular}

${ }^{a}$ Detection and quantification transitions

b Confirmation transitions

${ }^{\mathrm{c}}$ In the majority of experiments, complexes of $\mathrm{AOH}$ and $\mathrm{AE}$ were used as precursor ions

this corresponds to a transfer from $\mathrm{m} / \mathrm{z}=526$ to $\mathrm{m} / \mathrm{z}=164$ (loss of a unit with $m / z=362$ ). The repeatedly appearing signal at $\mathrm{m} / \mathrm{z}=77$ originates from the cleavage of the benzene ring in the PIC unit, whereas the signal at $\mathrm{m} /$ $z=45$ originates from $\mathrm{HOCH}_{2} \mathrm{CH}_{2}$. ethoxyl groups.

\section{Optimization of the Derivatization Procedure}

In order to ensure that the derivatization procedure is repeatable and efficient, it has been optimized in terms of reaction temperature, reaction time and the amount of the derivatization agent. All the studies were conducted for a mixture of $\mathrm{C}_{12} \mathrm{OH}$ and $\mathrm{C}_{12} \mathrm{EO}_{1-9}$.

During the first step, the influence of temperature on the formation of derivatives was analyzed. The reaction was carried out at temperature values ranging from 30 to $90{ }^{\circ} \mathrm{C}$ with a $10{ }^{\circ} \mathrm{C}$ interval. It was observed that the derivatization process may be conducted at $30^{\circ} \mathrm{C}$ for $\mathrm{C}_{12} \mathrm{OH}$, $\mathrm{C}_{12} \mathrm{EO}_{2}, \mathrm{C}_{12} \mathrm{EO}_{3}, \mathrm{C}_{12} \mathrm{EO}_{4}, \mathrm{C}_{12} \mathrm{EO}_{5}, \mathrm{C}_{12} \mathrm{EO}_{7}, \mathrm{C}_{12} \mathrm{EO}_{8}$ and $\mathrm{C}_{12} \mathrm{EO}_{9}$, since the highest peak areas were obtained for these compounds at these temperature values (Fig. 4). For each compound, with the exception of $\mathrm{C}_{12} \mathrm{EO}_{6}$, the increase in temperature did not significantly impact the increase or decrease in the peak area. It was also observed that the temperature of $70{ }^{\circ} \mathrm{C}$ is optimal for each of the studied $\mathrm{C}_{12} \mathrm{EO}_{1-2}$ homologues as well as $\mathrm{C}_{12} \mathrm{OH}$, since the derivatization process at this temperature value resulted in the highest peak areas. This is also the only value which allowed for maximum peak areas in the case of $\mathrm{C}_{12} \mathrm{EO}_{6}$. Therefore, the derivatization reaction was carried out at the temperature of $70{ }^{\circ} \mathrm{C}$ during subsequent studies.

The next optimization step was focused on the influence of time on the derivatization process. The derivatization reaction was conducted for periods of $10,20,30,40,50$ and $60 \mathrm{~min}$. Based on the obtained peak area values for all the studied compounds (which are shown on Fig. 5), it was established that time $=30 \mathrm{~min}$ is optimal for the derivatization process. After this time, the maximum values of peak areas were achieved for each component present in the studied mixture. It was also observed that in the case of $\mathrm{C}_{12} \mathrm{OH}, \mathrm{C}_{12} \mathrm{EO}_{2}, \mathrm{C}_{12} \mathrm{EO}_{3}, \mathrm{C}_{12} \mathrm{EO}_{4}, \mathrm{C}_{12} \mathrm{EO}_{5}, \mathrm{C}_{12} \mathrm{EO}_{6}$ and $\mathrm{C}_{12} \mathrm{EO}_{7}$ the reaction time did not influence the efficiency of the derivatization process. In the case of the remaining homologues, a reaction time lower than 30 min resulted in 

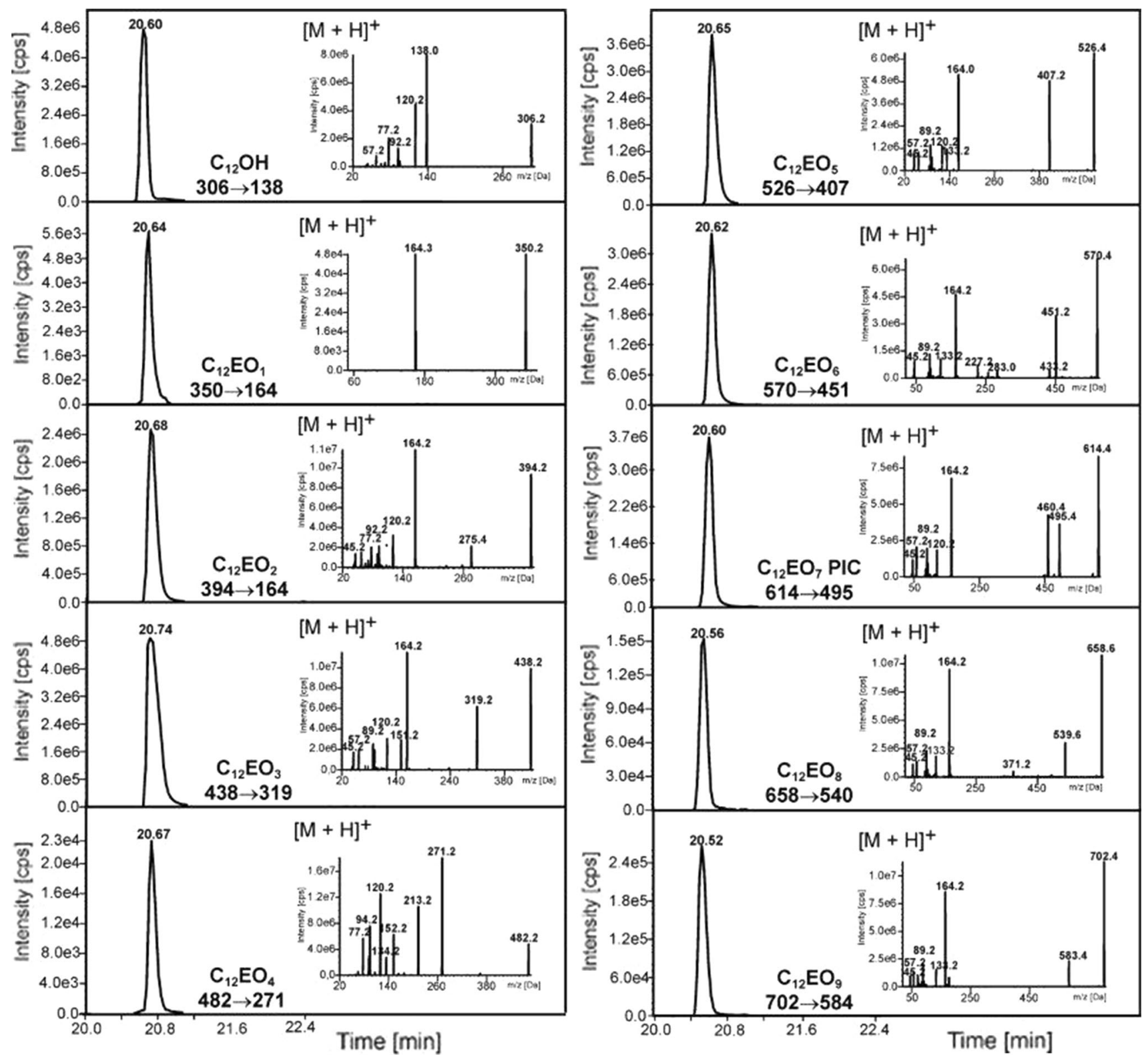

Fig. 2 Mass chromatograms of MRM pairs and fragmentation spectra originating from dodecanol and AE with PIC for protonated ions $[\mathrm{M}+\mathrm{H}]^{+}$ at the concentration of $1 \mathrm{~g} \mathrm{~mL}^{-1}$

decreased peak areas. Based on the results obtained during this step, a derivatization time of 30 min was used during subsequent studies.

The last optimization step was focused on the influence of the amount of derivatization agent relative to the studied mixture. The experiments were carried out using equimolar ratios of each component of the mixture relative to PIC (1:1) and different molar ratios: 1:1.25 (25\% excess of PIC), 1:1.5 (50\% excess of PIC) and 1:2 (100\% excess of PIC). On the basis of peak areas obtained for all studied compounds (Fig. 6), it was established that a $50 \%$ excess of the derivatization agent allowed to achieve maximum peak areas of each compound. Based on the analysis of Fig. 6, it was also observed that in case of $\mathrm{C}_{12} \mathrm{OH}, \mathrm{C}_{12} \mathrm{EO}_{2}, \mathrm{C}_{12} \mathrm{EO}_{3}$, $\mathrm{C}_{12} \mathrm{EO}_{5}, \mathrm{C}_{12} \mathrm{EO}_{6}$ and $\mathrm{C}_{12} \mathrm{EO}_{7}$ maximum peak areas may be achieved during derivatization without any excess of PIC and that these values do not change when excess of the derivatization agent is used. In case of the remaining compounds an excessive amount of PIC is necessary in order to achieve maximum peak areas. Based on the obtained results, a 50\% excess of PIC relative to each mixture component was used during subsequent studies (the reaction was carried out at a 1:1.5 ratio). 

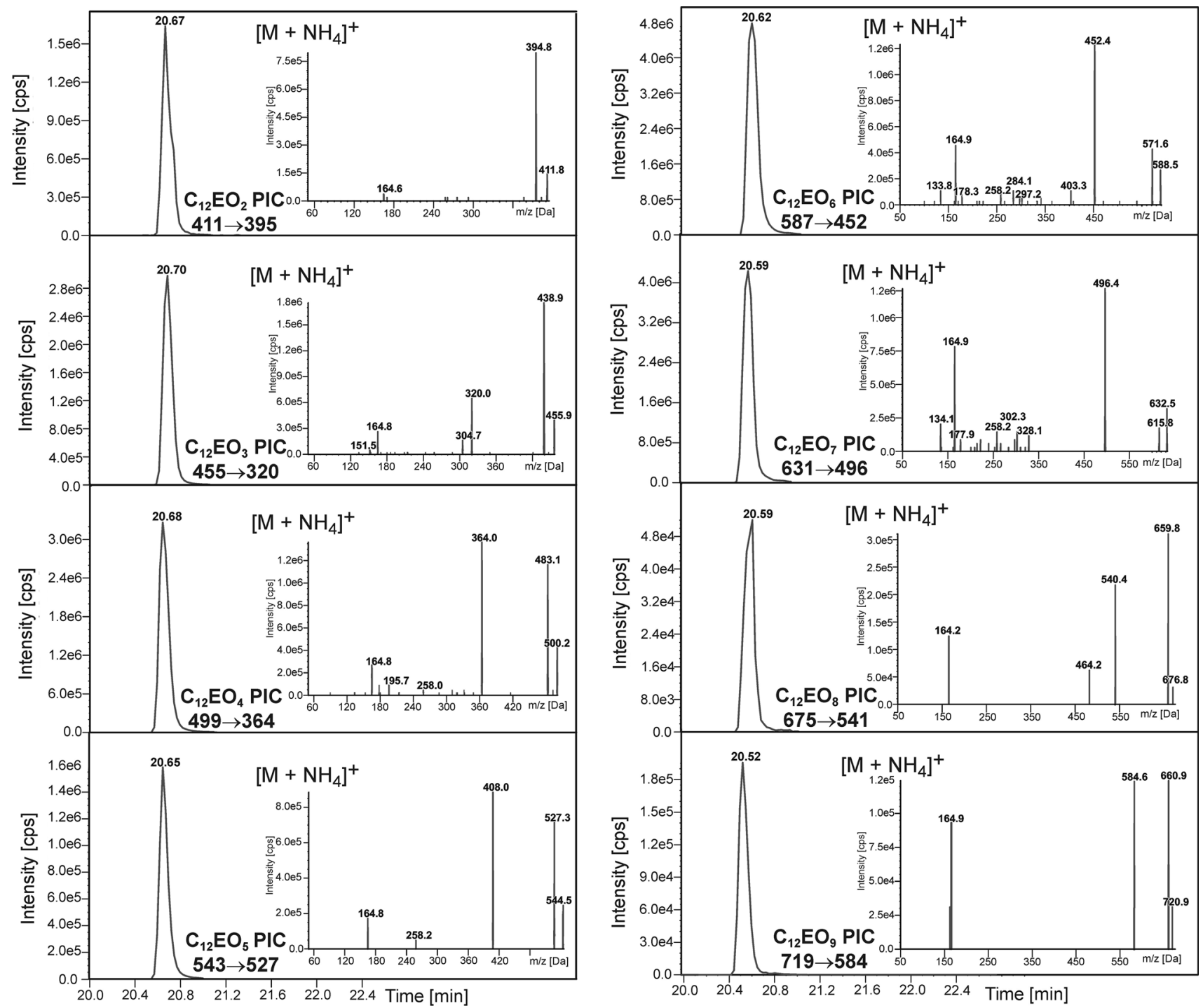

Fig. 3 Mass chromatograms of MRM pairs and fragmentation spectra originating from dodecanol and AE with PIC for ammoniated ions $\left[\mathrm{M}+\mathrm{NH}_{4}\right]^{+}$at the concentration of $1 \mathrm{~g} \mathrm{~mL}^{-1}$

\section{Method Validation}

Linearity, LOD and LOQ were determined for $[\mathrm{M}+\mathrm{H}]^{+}$ ions and $\left[\mathrm{M}+\mathrm{NH}_{4}\right]^{+}$ions (see Table 2). Linearity was tested by analyzing free dodecanol samples and ethoxylated alcohol at different concentrations, ranging from 0.005 to $1000 \mu \mathrm{g} \mathrm{L}^{-1}$. Good linearity was achieved for all compounds, with correlation coefficients $>0.97$ (see Table 2). In the studied concentration range only $\mathrm{C}_{12} \mathrm{EO}_{8}$ and $\mathrm{C}_{12} \mathrm{EO}_{9}$ exhibited a single linearity range for protonated adducts. The remaining protonated or ammoniated adducts of $\mathrm{C}_{12} \mathrm{OH}$ and $\mathrm{AE}$ derivatives exhibited two linearity ranges in the studied concentration range. The LOD ranged from $0.005 \mu \mathrm{g} \mathrm{L}^{-1}$ for $\mathrm{C}_{12} \mathrm{OH}$ and $\mathrm{C}_{12} \mathrm{EO}_{2-7}$ to $1 \mu \mathrm{g} \mathrm{L}^{-1}$ for $\mathrm{C}_{12} \mathrm{EO}_{1}$. The LOQ ranged from $0.01 \mu \mathrm{g} \mathrm{L}^{-1}$ for $\mathrm{C}_{12} \mathrm{EO}_{5-7}$ to $2 \mu \mathrm{g} \mathrm{L}^{-1}$ for $\mathrm{C}_{12} \mathrm{EO}_{1}$. The MQL (method limit of quantification) values for river water samples ranged from $0.0008 \mu \mathrm{g} \mathrm{L}^{-1}$ for $\mathrm{C}_{12} \mathrm{EO}_{5}$ and $\mathrm{C}_{12} \mathrm{EO}_{6}$ to $0.1 \mu \mathrm{g} \mathrm{L}^{-1}$ for $\mathrm{C}_{12} \mathrm{EO}_{1}$, whereas MDL (method limit of detection) values ranged from $0.0007 \mu \mathrm{g} \mathrm{L}^{-1}$ for $\mathrm{C}_{12} \mathrm{EO}_{8}$ to $0.06 \mu \mathrm{g} \mathrm{L}^{-1}$ for $\mathrm{C}_{12} \mathrm{EO}_{1}$. After considering the injection volume, which amounted to $10 \mu \mathrm{L}$, the MDL values range from $0.007 \mathrm{pg}$ for $\mathrm{C}_{12} \mathrm{EO}_{8}$ to $0.6 \mathrm{pg}$ for $\mathrm{C}_{12} \mathrm{OH}$. The MDL values obtained for river water are at least one order of magnitude lower compared to those obtained by Crescenzi et al. [30]. It should be noted, that the MDL depends on the matrix as well as separation and concentration techniques which were used during sample preparation. Crescenzi et al. [30] separated the ethoxylates using SPE on a GCB column, while the LOD and LOQ were determined against an internal standard $\left(\mathrm{C}_{10} \mathrm{EO}_{6}\right)$ based on a single chromatographic peak for the complete $\mathrm{C}_{12} \mathrm{EO}_{x}$ series obtained 
Fig. 4 Influence of the temperature of derivatization reaction on the peak areas for derivatives of $\mathrm{C}_{12} \mathrm{OH}$ and $\mathrm{C}_{12} \mathrm{EO}_{1-9}$ with PIC. Asterisk the bars in the graph are standard error bars

Fig. 5 Influence of the time of derivatization reaction on the peak areas for derivatives of $\mathrm{C}_{12} \mathrm{OH}$ and $\mathrm{C}_{12} \mathrm{EO}_{1-9}$ with PIC. Asterisk The bars in the graph are standard error bars
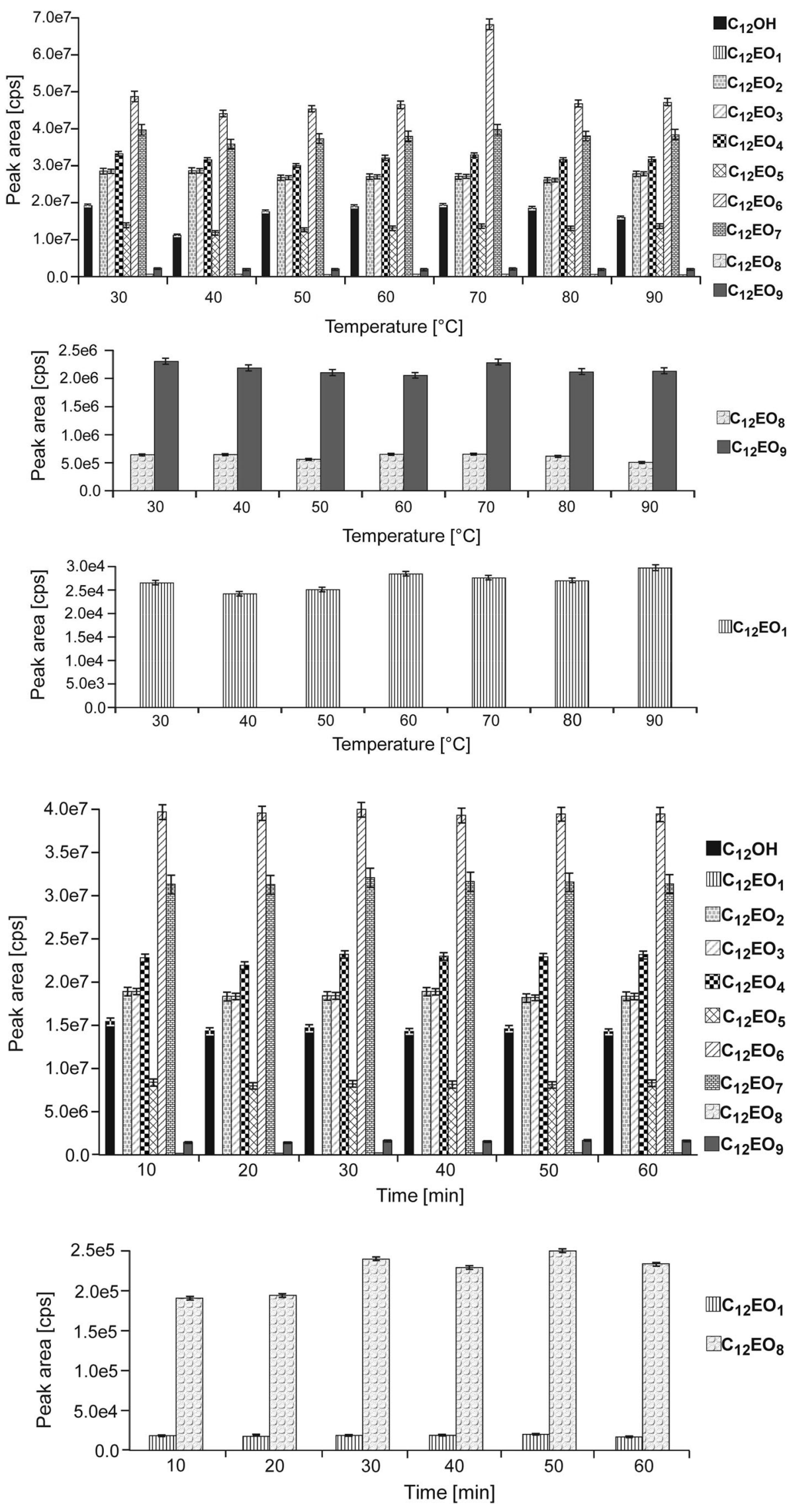
Fig. 6 Influence of the amount of derivatization agent of derivatization reaction on the peak areas for derivatives of $\mathrm{C}_{12} \mathrm{OH}$ and $\mathrm{C}_{12} \mathrm{EO}_{1-9}$ with PIC. Asterisk The bars in the graph are standard error bars
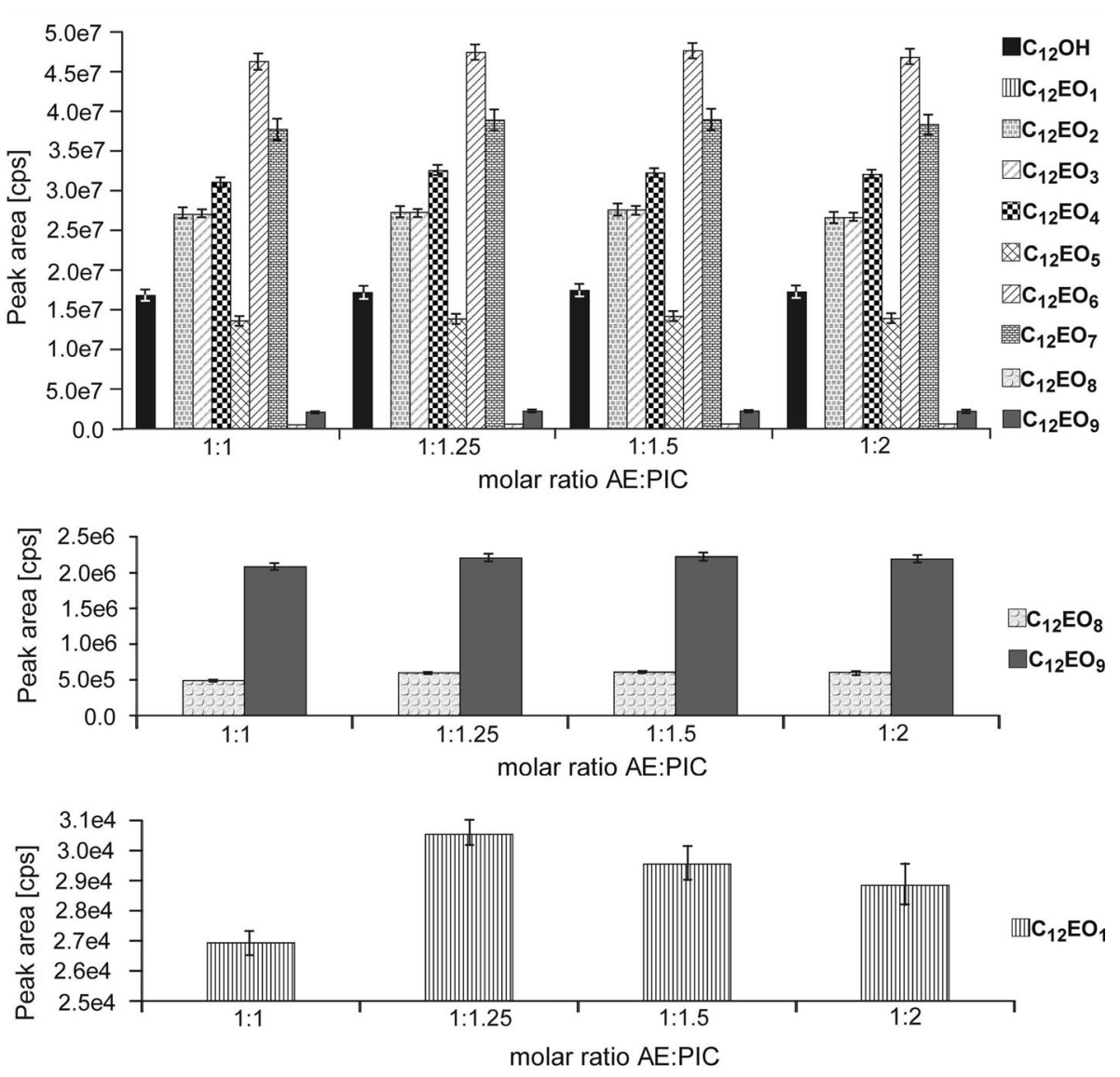

Table 2 Validation data for determination of $\mathrm{C}_{12} \mathrm{OH}$ and $\mathrm{C}_{12} \mathrm{EO}_{1-9}$

\begin{tabular}{|c|c|c|c|c|c|c|c|c|}
\hline Compound & $\begin{array}{l}\text { Calibration curve } \\
\text { range }\left(\mu \mathrm{g} \mathrm{L}^{-1}\right)\end{array}$ & $\begin{array}{l}\text { Correlation } \\
\text { coefficient }\left(r^{2}\right)\end{array}$ & $\begin{array}{l}\text { Calibration curve } \\
\text { range }\left(\mu \mathrm{g} \mathrm{L}^{-1}\right)\end{array}$ & $\begin{array}{l}\text { Correlation } \\
\text { coefficient }\left(r^{2}\right)\end{array}$ & $\begin{array}{l}\text { LOD } \\
\left(\mu \mathrm{g} \mathrm{L}^{-1}\right)\end{array}$ & $\begin{array}{l}\mathrm{MDL} \\
\left(\mu \mathrm{g} \mathrm{L}^{-1}\right)\end{array}$ & $\begin{array}{l}\mathrm{LOQ} \\
\left(\mu \mathrm{g} \mathrm{L}^{-1}\right)\end{array}$ & $\begin{array}{l}\mathrm{MQL} \\
\left(\mu \mathrm{g} \mathrm{L}^{-1}\right)\end{array}$ \\
\hline $\begin{array}{l}\mathrm{C}_{12} \mathrm{OH} \\
{[\mathrm{M}+\mathrm{H}]^{+}}\end{array}$ & $0.05-200$ & 0.9984 & $200-1000$ & 0.8707 & 0.005 & 0.0004 & 0.05 & 0.004 \\
\hline $\begin{array}{l}\mathrm{C}_{12} \mathrm{EO}_{1} \\
{[\mathrm{M}+\mathrm{H}]^{+}}\end{array}$ & $2-200$ & 0.9997 & 200-1000 & 0.9943 & 1 & 0.06 & 2 & 0.1 \\
\hline $\begin{array}{l}\mathrm{C}_{12} \mathrm{EO}_{2} \\
{[\mathrm{M}+\mathrm{H}]^{+}}\end{array}$ & $0.05-200$ & 0.9988 & $200-1000$ & 0.9882 & 0.005 & 0.0005 & 0.05 & 0.005 \\
\hline $\begin{array}{c}\mathrm{C}_{12} \mathrm{EO}_{3} \\
{[\mathrm{M}+\mathrm{H}]^{+}}\end{array}$ & $0.02-200$ & 0.9983 & 200-1000 & 0.9918 & 0.005 & 0.0004 & 0.02 & 0.002 \\
\hline $\begin{array}{l}\mathrm{C}_{12} \mathrm{EO}_{4} \\
{\left[\mathrm{M}+\mathrm{NH}_{4}\right]^{+}}\end{array}$ & $0.05-200$ & 0.9992 & 200-1000 & 0.9900 & 0.005 & 0.0004 & 0.05 & 0.004 \\
\hline $\begin{array}{l}\mathrm{C}_{12} \mathrm{EO}_{5} \\
{[\mathrm{M}+\mathrm{H}]^{+}}\end{array}$ & $0.01-200$ & 0.9988 & $200-1000$ & 0.9691 & 0.005 & 0.0004 & 0.01 & 0.0008 \\
\hline $\begin{array}{l}\mathrm{C}_{12} \mathrm{EO}_{6} \\
{\left[\mathrm{M}+\mathrm{NH}_{4}\right]^{+}}\end{array}$ & $0.01-200$ & 0.9992 & $200-1000$ & 0.9706 & 0.005 & 0.0004 & 0.01 & 0.0008 \\
\hline $\begin{array}{l}\mathrm{C}_{12} \mathrm{EO}_{7} \\
\quad\left[\mathrm{M}+\mathrm{NH}_{4}\right]^{+}\end{array}$ & $0.01-200$ & 0.9992 & 200-1000 & 0.9928 & 0.005 & 0.0006 & 0.01 & 0.001 \\
\hline $\begin{array}{l}\mathrm{C}_{12} \mathrm{EO}_{8} \\
{[\mathrm{M}+\mathrm{H}]^{+}}\end{array}$ & $0.05-1000$ & 0.9971 & - & - & 0.01 & 0.0007 & 0.05 & 0.004 \\
\hline $\begin{array}{l}\mathrm{C}_{12} \mathrm{EO}_{9} \\
{[\mathrm{M}+\mathrm{H}]^{+}}\end{array}$ & $0.01-1000$ & 0.9982 & - & - & 0.005 & 0.0004 & 0.01 & 0.007 \\
\hline
\end{tabular}


in TIC (total ion current) mode. The identification of the mixture was conducted by analysis of mass spectrum for this peak. Therefore, the determined LOD and LOQ values as well as concentrations in the actual samples are for the sum of the total $\mathrm{C}_{12} \mathrm{EO}_{x}$ series, not for specific ethoxylated alcohols in the $\mathrm{C}_{12} \mathrm{EO}_{x}$ series, as in this study. The presented study employed classic LLE technique with ethyl acetate, and the LOD, LOQ values as well as concentrations of $\mathrm{C}_{12} \mathrm{OH}$ and $\mathrm{C}_{12} \mathrm{EO}_{1-9}$ in river water were determined using the analyzed compounds as standards (the areas of chromatographic peaks). Each of the determined ethoxylated alcohols was a separated, single peak, due to the use of single homologues and the MRM mode during their detection with the MS/MS technique and prior derivatization with the use of PIC. The only limitation of the presented methodology is the lack of single homologues with more than 9 ethoxyl groups in the structure of the $\mathrm{C}_{12} \mathrm{EO}_{\mathrm{x}}$ compound series on the market, since such compounds are also present in surface water as confirmed by literature references [2].

The LOD values are not equal for all the studied ethoxylated alcohol homologues. Such differences result from different responses of the detector, which are influenced by ionization. Such dependencies were observed during direct determination (without derivatization) of these compounds using the LC-MS/MS technique [23]. Perhaps the length of the ethoxyl chain influences the ionization process. With the increase of the ethoxyl chain length up to a certain value more stable complexes are formed. These observations were also described by Crescenzi et al. [30]. The authors observed that the response of the detector increased exponentially with the increase of the amount of ethoxyl groups in the compounds from 1 to 6. This dependency was not observed for ethoxylated alcohols with a number of ethoxyl groups higher than 6 .

The determined LOD and LOQ values for AE derivatives with phenyl isocyanate were lower by two orders of magnitude compared to values obtained for the direct determination method of these compounds using LC-MS/ MS in the form of protonated adducts [23]. Additionally, the LOD values obtained in the framework of this study were lower by one order of magnitude compared to LOD values obtained for derivatives of and $\mathrm{C}_{12} \mathrm{EO}_{1-6}$ with 1-naphthoyl chloride using the same technique [18].

\section{River Water Sample}

In order to check whether the described method may be used for determination of $\mathrm{C}_{12} \mathrm{OH}$ and $\mathrm{C}_{12} \mathrm{EO}_{1-9}$ in actual environmental samples, the compounds were determined in a non-spiked and spiked (at three concentration levels: 2, 4 and $8 \mu \mathrm{g} \mathrm{L}^{-1}$ ) river water samples (River Warta, Poznan, Poland). Ethyl acetate was used for LLE. Separation and determination was performed in accordance with sections Derivatization and Liquid chromatography-tandem mass spectrometry. The results are shown in Table 3. The concentration values of specific analytes present in the nonspiked Warta river water samples were determined using the multiple standard addition method [37].

All of the studied analytes were identified in the Warta river water samples. The highest concentrations were determined for dodecanol $\left(10 \mu \mathrm{g} \mathrm{L}^{-1}\right)$ whereas the lowest were observed for $\mathrm{C}_{12} \mathrm{EO}_{6}$ and $\mathrm{C}_{12} \mathrm{EO}_{7}\left(0.06 \mu \mathrm{g} \mathrm{L}{ }^{-1}\right)$. The obtained concentrations of $\mathrm{C}_{12} \mathrm{EO}_{2}-\mathrm{C}_{12} \mathrm{EO}_{9}$ homologues were at a similar level compared to the results described by Zembrzuska et al. regarding the monitoring of Warta river during a period from October 2011 to September 2012 [37]. The authors determined non-derivatized AE using LC-MS/ MS. It was observed that the obtained recovery rates for higher additions of the model mixture were higher compared to recovery rates obtained for lower additions of the model mixture. It was also observed that in case of additions of 4 and $8 \mu \mathrm{g} \mathrm{L}^{-1}$, the recovery rates increased along with the increase of the ethoxy chain length in the surfactant molecule. The same dependencies, namely higher concentrations of AE containing single ethoxyl groups in the compound and free alcohol, were observed by other research groups [7, 40], which indicates that central fission is the dominating biodegradation mechanism and the source of free alcohol in surface water and treated wastewater. Since the alcohol ethoxylates $\mathrm{C}_{12-13}$ with low EO groups are characterized by high toxicity $[7,41]$, their monitoring is crucial for proper environmental protection. The observation of their concentration in the environment is associated with the use of sensitive, selective analytical methods which allow one to precisely determine their content. The LC-MS/MS in MRM mode may be a solution for determination of $\mathrm{AE}$ derivatives with PIC. Employing this technique allows one to eliminate the additional peaks associated with the presence of derivatives of other contaminants in the river water samples, which were observed during UV detection [16].

Due to the low level of analyte and the complex matrix, the use of derivatization allowed to us increase the sensitivity and range of determined AE (with 1-2 ethoxyl groups and free alcohol) in comparison to detection of nonderivatized compounds [23]. Furthermore, the use of derivatization caused an increase in volatility during ionization in the ESI source and changed the behavior of compounds during their chromatographic separation, which allowed to use the $\mathrm{C} 18$ column for separation of $\mathrm{AE}$ based on the ethoxyl chain length in a reversed phase system, which is not possible without derivatization, MS/ 
Table 3 Concentrations of $\mathrm{C}_{12} \mathrm{OH}$ and homogeneous AE in Warta River in March 2015, and recoveries of spikes of $\mathrm{C}_{12} \mathrm{OH}_{\text {and }} \mathrm{C}_{12} \mathrm{EO}_{1-9} \mathrm{Warta}$ River

\begin{tabular}{|c|c|c|c|c|c|c|c|}
\hline \multirow[t]{2}{*}{ Homologue } & \multirow{2}{*}{$\begin{array}{l}\text { River water } \\
\text { found } \\
\left(\mu \mathrm{g} \mathrm{L}^{-1}\right) \pm \mathrm{SD}\end{array}$} & \multicolumn{2}{|l|}{ Spike $2 \mu \mathrm{g} \mathrm{L}^{-1}$} & \multicolumn{2}{|c|}{ Spike $4 \mu \mathrm{g} \mathrm{L}^{-1}$} & \multicolumn{2}{|l|}{ Spike $8 \mu \mathrm{g} \mathrm{L}^{-1}$} \\
\hline & & $\begin{array}{l}\text { Found }(\mu \mathrm{g} \\
\left.\mathrm{L}^{-1}\right) \pm \mathrm{SD}\end{array}$ & $\begin{array}{l}\text { Recovery } \\
(\%)\end{array}$ & $\begin{array}{l}\text { Found }(\mu \mathrm{g} \\
\left.\mathrm{L}^{-1}\right) \pm \mathrm{SD}\end{array}$ & $\begin{array}{l}\text { Recovery } \\
(\%)\end{array}$ & $\begin{array}{l}\text { Found }(\mu \mathrm{g} \\
\left.\mathrm{L}^{-1}\right) \pm \mathrm{SD}\end{array}$ & $\begin{array}{l}\text { Recovery } \\
(\%)\end{array}$ \\
\hline $\mathrm{C}_{12} \mathrm{OH}$ & $10.00 \pm 0.28$ & $10.32 \pm 0.28$ & 16.0 & $12.04 \pm 0.33$ & 51.0 & $16.24 \pm 0.35$ & 78.0 \\
\hline $\mathrm{C}_{12} \mathrm{EO}_{1}$ & $2.19 \pm 0.04$ & $2.75 \pm 0.07$ & 28.0 & $3.98 \pm 0.07$ & 44.8 & $8.66 \pm 0.15$ & 80.9 \\
\hline $\mathrm{C}_{12} \mathrm{EO}_{2}$ & $1.20 \pm 0.03$ & $2.18 \pm 0.06$ & 49.0 & $4.37 \pm 0.11$ & 79.3 & $8.53 \pm 0.23$ & 91.6 \\
\hline $\mathrm{C}_{12} \mathrm{EO}_{3}$ & $0.56 \pm 0.01$ & $1.59 \pm 0.03$ & 51.5 & $3.84 \pm 0.07$ & 82.0 & $7.98 \pm 0.11$ & 92.8 \\
\hline $\mathrm{C}_{12} \mathrm{EO}_{4}$ & $0.55 \pm 0.01$ & $1.82 \pm 0.03$ & 63.5 & $3.84 \pm 0.07$ & 82.3 & $7.72 \pm 0.11$ & 89.6 \\
\hline $\mathrm{C}_{12} \mathrm{EO}_{5}$ & $0.36 \pm 0.02$ & $1.85 \pm 0.08$ & 74.5 & $3.87 \pm 0.18$ & 87.8 & $7.51 \pm 0.34$ & 89.4 \\
\hline $\mathrm{C}_{12} \mathrm{EO}_{6}$ & $0.06 \pm 0.01$ & $1.33 \pm 0.03$ & 63.5 & $3.07 \pm 0.07$ & 72.3 & $6.84 \pm 0.13$ & 84.8 \\
\hline $\mathrm{C}_{12} \mathrm{EO}_{7}$ & $0.06 \pm 0.01$ & $1.28 \pm 0.04$ & 61.0 & $3.15 \pm 0.11$ & 77.3 & $6.79 \pm 0.22$ & 84.1 \\
\hline $\mathrm{C}_{12} \mathrm{EO}_{8}$ & $0.24 \pm 0.01$ & $1.66 \pm 0.01$ & 71.0 & $3.37 \pm 0.02$ & 78.3 & $6.87 \pm 0.06$ & 82.9 \\
\hline $\mathrm{C}_{12} \mathrm{EO}_{9}$ & $0.13 \pm 0.01$ & $1.51 \pm 0.03$ & 69.0 & $3.61 \pm 0.08$ & 87.0 & $6.54 \pm 0.15$ & 80.1 \\
\hline
\end{tabular}

MS detection in MRM mode and the use of expensive chromatographic columns [23].

\section{Concluding Remarks}

The described method for determination of dodecanol and $\mathrm{C}_{12} \mathrm{EO}_{1-9}$ in the form of derivatives with phenyl isocyanate using the LC-MS/MS technique is characterized by lower LOD and LOQ values compared to other determination methods of these compounds, in the form of derivatives with other derivatization agents [18] as well as nonderivatized form using LC-MS/MS [23]. In combination with liquid-liquids extraction using ethyl acetate, this method is an appropriate and sensitive analytical tool for the monitoring of environmental water samples.

Acknowledgements This work was performed with the financial support of 03/31/DSPB/0338 from the Polish Ministry of Science and Higher Education.

Open Access This article is distributed under the terms of the Creative Commons Attribution 4.0 International License (http://crea tivecommons.org/licenses/by/4.0/), which permits unrestricted use, distribution, and reproduction in any medium, provided you give appropriate credit to the original author(s) and the source, provide a link to the Creative Commons license, and indicate if changes were made.

\section{References}

1. Plata MR, Contento AM, Ríos Á. Analytical characterization of alcohol-ethoxylate substances by instrumental separation techniques. TrAC. 2011;30:1018-34.

2. Kopiec D, Zembrzuska J, Budnik I, Wyrwas B, Dymaczewski Z, Komorowska-Kaufman M, Lukaszewski Z. Identification of non- ionic surfactants in elements of the aquatic environment. Tenside Surf Det. 2015;52:380-5.

3. Plata MR, Contento AM, Ríos Á. Analytical characterization of PEG polymers by MEKC. Electrophoresis. 2010;31:679-87.

4. Patterson SJ, Scott CC, Tucker KBE. Non-ionic detergent degradation. I. Thinlayer chromatography and foaming properties of alcohol polyethoxylates. J Am Oil Chem Soc. 1967;44:407-12.

5. Zembrzuska J, Budnik I, Lukaszewski Z. Parallel pathways of ethoxylated alcohol biodegradation under aerobic conditions. Sci Total Environ. 2016;557-558:612-9.

6. Schröder HF. Tracing of surfactants in the biological wastewater treatment process and the identification of their metabolites by flow injection-mass spectrometry and liquid chromatographymass spectrometry and -tandem mass spectrometry. J Chromatogr A. 2001;926:127-50.

7. Eadsforth CV, Sherren AJ, Selby MA, Toy R, Eckhoff WS, McAvoy DC, Matthijs E. Monitoring of environmental fingerprints of alcohol ethoxylates in Europe and Canada. Ecotoxicol Environ Saf. 2006;64:14-29.

8. Asmussen C, Stan HJ. Determination of non-ionic surfactants of the alcohol polyethoxylate type by means of high temperature gas chromatography and atomic emission detection. J High Res Chromatog. 1998;21:597-604.

9. Jandera P, Holčapek M, Theodoridis G. Investigation of chromatographic behavior of ethoxylated alcohol surfactants in normal-phase and reversed-phase systems using high-performance liquid chromatography-mass spectrometry. J Chromatogr A. 1998;813:299-311.

10. Zanette M, Marcomini A, Marchiori E, Samperi R. High-performance liquid chromatographic-fluorescence determination of aliphatic alcohol polyethoxylates and poly(ethylene glycol)s in aqueous samples. J Chromatogr A. 1996;757:159-74.

11. Gomez V, Ferreres L, Pocurull E, Borrull F. Determination of non-ionic and anionic surfactants in environmental water matrices. Talanta. 2011;84:859-66.

12. Heinig K, Vogt C, Werner G. Separation of nonionic surfactants by capillary electrophoresis and high-performance liquid chromatography. Anal Chem. 1998;70:1885-92.

13. Koike R, Kitagawa F, Otuska K. Separation of fatty alcohol ethoxylates by capillary zone electrophoresis and micellar electrokinetic chromatography. J Sep Sci. 2009;32:399-407. 
14. Arias M, Bauza R, Rodríguez J, Castaňeda G, Ríos Á. Rapid characterization of fatty alcohol ethoxylates by non-aqueous capillary electrophoresis. Electrophoresis. 2008;29:3060-8.

15. Lemr K. Homologue separation of linear alcohol ethoxylates by high-performance liquid chromatography. J Chromatogr A. 1996;732:299-305.

16. Nitschke L, Huber L. Analysis of ethoxylated alcohol surfactants in water by HPLC. Fresenius J Anal Chem. 1993;345:585-8.

17. Schmitt TM, Allen MC, Brain DK, Guin KF, Lemmel DE, Osburn QW. HPLC determination of ethoxylated alcohol surfactants in wastewater. J Am Oil Chem Soc. 1990;67:103-9.

18. Zgola-Grześkowiak A, Grześkowiak T. Solid-phase extraction combined with dispersive liquid-liquid microextraction, fast derivatization and high performance liquid chromatography-tandem mass spectrometry analysis for trace determination of shortchained dodecyl alcohol ethoxylates and dodecyl alcohol in environmental water samples. J Chromatogr A. 2012;1251:40-7.

19. Trathnigg B. Determination of MWD and chemical composition of polymers by chromatographic techniques. Prog Polym Sci. 1995;20:615-50.

20. Cretier G, Podevin C, Rocca J-L. Analysis of aliphatic alcohol ethoxylates in terms of alkyl and ethylene oxide chain lengths by reversed-phase liquid chromatography with evaporative scattering detection. J Chromatogr. 2000;874:305-10.

21. Escrig-Doménech A, Simó-Alfonso EF, Ramis-Ramos G. Determination of four major surfactant classes in cleaning products by reversed-phase liquid chromatography using serially connected UV and evaporative light-scattering detection. Anal Chim Acta. 2016;932:106-13.

22. Nowicka D, Budnik I, Zembrzuska J. Biodegradation of alcohol ethoxylates by bacterial consortium from industrial wastewater. Tenside Surfact Det. 2013;50:31-5.

23. Zembrzuska J, Budnik I, Lukaszewski Z. Separation and determination of homogenous fatty alcohol ethoxylates by liquid chromatography with multistage mass spectrometry. J Sep Sci. 2014;37:1694-702.

24. Lara-Martín PA, González-Mazo E, Browwnawell BJ. Environmental analysis of acohol ethoxylates and nonylphenol ethoxylate metabolites by ultra-performance liquid chromatography-tandem mass spectrometry. Anal Bioanal Chem. 2012;402:2359-68.

25. Krogh KA, Bügel Mogensen B, Halling-Sørensen B, Cortés A, Vejrup KV. Analysis of alcohol ethoxylates and alkylamine ethoxylates in agricultural soils using pressurized liquid extraction and liquid chromatography-mass spectrometry. Anal Bioanal Chem. 2003;376:1089-97.

26. Ma Q, Ma W, Chen X, Wang Z, Bai H, Zhang L, Li W, Wang Ch, $\mathrm{Li}$ X. Comprehensive analysis of fatty alcohol ethoxylates by ultra-high pressure hydrophilic interaction chromatography coupled with ion mobility spectrometry mass spectrometry using a custom-designed sub-2 $\mu \mathrm{m}$ column. J Sep Sci. 2015;38:2182-91.

27. Micò-Tormos A, Bianchi F, Simò-Alfonso EF, Ramis-Ramos G. Determination of fatty alcohol ethoxylates with diphenic anhydride derivatization and liquid chromatography with spectrophotometric detection. A comparative study with other anhydrides. J Chromatogr A. 2009;1216:3023-30.

28. Ionescu M, Petrović ZS, Wan X. Ethoxylated soybean polyols for polyurethanes. J Polym Environ. 2010;18:1-7.

29. Cassani G, Pratesi C, Faccetti L, Pravettoni S, Nucci G, Andrioll $\mathrm{N}$, Valtorta L, Matheson L. Characterization of alcohol ethoxylates as alcohol ethoxy sulfate derivatives by liquid chromatography-mass spectrometry. J Surfactants Deterg. 2004;7(2):195-202.

30. Crescenzi C, Di Corcia A, Samperi R. Determination of nonionic polyethoxylate surfactants in environmental waters by liquid chromatography/electrospray mass spectrometry. Anal Chem. 1995;67:1797-804.

31. Iwasaki Y, Nakano Y, Mochizuki K, Nomoto M, Takahashi Y, Ito R, Saito K, Nakazawa H. A new strategy for ionization enhancement by derivatization for mass spectrometry. J Chromatogr B. 2011;879:1159-65.

32. Zu C, Praay HN, Bell BM, Redwine OD. Derivatization of fatty alcohol ethoxylate non-ionic surfactants using 2-sulfobenzoic anhydride for characterization by liquid chromatography/mass spectrometry. Rapid Commun Mass Sp. 2010;24:120-8.

33. Dunphy CJ, Pessler DG, Morrall SW. Derivatization LC/MS for simultaneous determination of fatty alcohol and alcohol ethoxylate surfactants in water and wastewater samples. Envir Sci Tech. 2001;35:1223-30.

34. Escrig-Doménech A, Simó-Alfonso EF, Herrero-Martinez JM, Ramis-Ramos G. Derivatization of hydroxyl functional groups for liquid chromatography and capillary electroseparation. J Chromatogr A. 2013;1296:140-56.

35. Sparham CJ, Bromilow ID, Dean JR. SPE/LC/ESI/MS with phthalic anhydride derivatization for the determination of alcohol ethoxylate surfactants in sewage influent and effluent samples. J Chromatogr A. 2005;10662:39-47.

36. Cassani G, Tibaldi F, Donato G, Andriollo N. Determination of alcohol ethoxylates derivatized with Naphthoyl chloride, in waste water treatment plant influent, effluent and sludge samples by liquid chromatography mass spectrometry. J Surfactants Deterg. 2011;14:139-50.

37. Zembrzuska J, Budnik I, Lukaszewski Z. Monitoring of selected non-ionic surfactants in river water by liquid chromatographytandem mass spectrometry. J Environ Manage. 2016;169:247-52.

38. Morrall SW, Dunphy JC, Cano ML, Evans A, McAvoy DC, Price $\mathrm{PB}$, Eckhoff WS. Removal and environmental exposure of alcohol ethoxylates in US sewage treatment. Ecotoxicol Environ Saf. 2006;64:3-13.

39. Wells G, Prest H, Russ IV CW (2011) Signal, noise, and detection limits in mass spectrometry. Technical Note. Agilent Technologies Wilmington USA

40. Belanger SE, Dorn PB, Toy R, Boeije G, Marshall SJ, Wind T, Van Compernolle R, Zeller D. Aquatic risk assessment of alcohol ethoxylates in North America and Europe. Ecotoxicol Environ Saf. 2006;64:85-99.

41. Wong DCL, Dorn PB, Chai EY. Acute Toxicity and structureactivity relationships of nine alcohol ethoxylate surfactants to fathead minnow and Daphnia magna. Environ Toxicol Chem. 1997;16:1970-6.

Joanna Zembrzuska graduated from the Poznan University of Technology in 1999 and she finished her Ph.D. in 2003 there. Since then, she has been working as an Assistant Professor at the Poznan University of Technology. Her research interests include determination of non-ionic surfactants and pharmaceutical residues in environmental by LC-MS/MS and selenium speciation. 